\title{
Uma tentativa de interpretaçào teórica do extrativismo amazônico
}

\author{
Alfredo Kingo Oyama Homma (*)
}

\begin{abstract}
Resumo
E proposto um modelo teórico para interpretar o processo extrativo, caracterizando dois tipos distintos: o de coleta e o de aniquilamento, șugerindo tratamentos diferenciados na exploração, preservação e conservaçăo. Explicação da dinâmica do processo extrativo, inicio e final e a dificuldade de compatibilizar bens livres e bens de mercado com vistas à conservação e preservação dos recursos naturais e sua exploração econômica.
\end{abstract}

\section{INTRODUÇÃo}

O processo extrativo sempre foi entendido como primeira forma de exploração econômica, limitando a coleta de produtos existen. tes na natureza, com baixa produtividade ou produtividade declinanie, decorrentes do custo de oportunidade do trabalho próximo do zero ou do alto preço unitário devido ao monopólio extrativo, (') tendendo a sua extinçăo com o correr do tempo. Muitas das antigas formas de extrativismo fazem parte hoje de culturas ou criações racionais, outras desa. pareceram, algumas estão $\mathrm{em}$ vias de processo de domesticação e novas atividades extrativas poderão surgir.

$\mathrm{O}$ fato de as atividades extrativas estarem relacionadas com o asgotamento desses recursos, que em alguns casos são de propriedade comum, com exceção do ar, são localizados afetos aos efeitos extornos da exploração pelo homem tem motivado ultimamente o aparecimento de certas medidas de sentido conservacionista, notadamente as relacionadas com a proteção da floresta amazônica.

A despeito da alta importância que o extrativismo tem desempenhado na formação econômica e social do Brasil, os enfoques de análise tem sido convencionais, bem como os tratamentos dispensados a este setor. A fronteira de conhecimento abrangida por vários autores diz respeito aos aspectos econômicos e sociais, da irracionalidade do sistema, da sua baixa produtividade e da necessidade de sua racionalização. São de caráter descritivo, sendo que não foi encontrada nenhuma referência com vistas a teorização econômica do processo (Benchimol, 1966; Mendes, 1971; Reis, 1953).

No caso da região amazônica, dada a quantidade da existência de seus recursos naturais, o extrativismo tem desempenhado um papel decisivo na formação econômica e social da região e do Brasil, sobretudo pela exploração extrativa da seringueira.

A pauta de produtos extrativos $\left({ }^{2}\right)$ atualmente explorada no Brasil é bastante extensa abrangendo borrachas, gomas não elásticas, ceras, fibras, sementes oleaginosas, tanantes, alimentícias, aromáticas, corantes, medicinais, tóxicos, madeira, caça e pesca, envolvendo grande parcela da população rural na coleta e nos processos de beneficiamento, industrialização e artesanato, formando diversos tipos característicos e peculiaridades regionais.

A pressuposição principal do extrativismo requer a existência de recursos naturais que tenham potencialidades para exploração econômica, quer através do seu consumo "in natura", beneficiamento ou industrialização. Requer também que estes produtos sejam competitivos em relação a determinados produtos substitutos ou comp!ementares ou a inexis-

(•) - Centro de Pesquisa Agropecuária do Trópico Úmido, Caixa Postal 48, Belém, Pará.

(1) - Em certas áreas do Nordeste dada a grande dispo nibilidade de măo-de-obra pode aventar-se a hipótese da manutenção do extrativismo como decorrente do baixo custo de oportunidade do trabalho.

(2) - Não é mencionado o extrativismo mineral por ser um recurso não renovável, portanto năo passível de exploração sustentada ao longo do tempo. 
tência de qualquer substituto no mercado. Em relação a estas consideraçōes e ao conceito geral do extrativismo, procuraremos discutir algumas implicações teóricas ligadas ao processo extrativista.

\section{Classificação do processo extrativista}

Os processos extrativistas podem ser classificados em dois grandes grupos quanto a sua forma de exploração: $\left({ }^{3}\right)$

EXTRATIVISMO POR ANIQUILAMENTO OU DEPREDAÇÃo - Quando a obtenção do recurso econômico implica na extinção dessa fonte, ou quando a velocidade de recuperação for inferior à velocidade de exploração extrativa. Trata-se, por exemplo, da extração madeireira. do palmito e da caça e pesca indiscriminadas; $\left({ }^{4}\right)$

eXTRATIVISMO DE COLETA - Quando a sua exploração é fundamentada na coleta de produtos extrativos oriundos de determinadas plantas ou animais. Nesse caso, é, comum forçar a obtenção de uma produtividade imediata, levando ao seu aniquilamento a médio e a longo prazo. Como exemplos desse grupo, temos a seringueira, a castanha-do-brasil etc. No caso em que a velocidade de extração for igual à velocidade de recuperação, o extrativismo permanecerá em equilibrio.

Em ambos os casos, as substituições por outras atividades econômicas $\left({ }^{5}\right)$ levam também ao seu total aniquilamento das antigas formas de exploração extrativa.

\section{INÍCIO DA EXPLORAÇÃo EXTRATIVY}

Certos recursos naturais tiveram a sua exploração acelerada nos dias atuais, culminando com o aparecimento de movimentos ecológicos contra esta destruição ou o aparecimento de novas formas extrativas a serem desenvolvidas. A intocabilidade pode ser cxplicada como sendo uma oferta potencial, cujo preço de exploração excede o preço da dem:anda potencial por este determinado produto.

Com o desenvolvimento da tecnologia, métodos de exploração ou com a melhoria das condições infraestruturais, as condições para o extrativismo são viabilizadas, induzindo ao início da exploração extrativa. Para alguns produtos com o crescimento da demanda e do caráter exclusivo do produto, o seu plantio em bases racionais é induzido com a disponibilidade de tecnologia de produção. Nesse caso, a seringueira e o guaraná são exemplos típicos de sua expansão em bases racionais e a castanha-do-brasil encontra-se em vias de domesticação através da pesquisa.

$O$ início da exploração pode ser entendido como tendo uma oferta potencial (S) bastante grande de determinado recurso natural como um bem livre e uma demanda potencial (D), inicialmente pequena (Fig. 1a.). Com o tempo, dado o crescimento do mercado, a meIhoria dos processos de transporte e comercialização e obras de infraestrutura, estas tenderiam a entrar no equilíbrio com o crescimento da demanda (Fig. 1b).

A intensificação da exploração de madeiras na' região amazônica pode ser entendida como o aumento gradativo da demanda por este produto, associado ao processo da implantação de grandes fazendas para criação bovina causando as grandes devastações na região em relação a duas ou três décadas anteriores. A abertura de estradas e o crescimento da demanda condicionaram a viabilidade econômica destas explorações.

(3) - Esta classificação feita para o desenvolvimento da teoria difere das usualmente conhecidas como recursos naturais renováveis e não renováveis feita por Hagget (Ritter, 1975). Não é considerado o caso de "belezas naturais" para fins turísticos que alguns autores caracterizam como recursos naturais.

(4) - 0 extrativismo mineral se inclui nesta categoria, com a diferença de que a sua exploração levará ao esgotamento definitivo, como é o caso das reservas petroliferas. Certas formas de agricultura predatória podem ser enquadradas nesta categoria, levando ao esgotamento do solo, erosão, etc.

(5) - A substituiçăo pode ser feita passando de um produto extrativo para outro em função dos preços e mercados condicionados pelo sistema social peculiar no extrativismo ou deslocado para outras atividades fora do setor." 
0 processo de "çueimadas" bastante típico na região amazônica, onde grandes quantidades de madeiras nobres são inutilizadas, a par dos aspectos culturais, exigüidade de tempo, custo de preparo da área mais econômica, fertilização do solo e manejo mais fácil, pode ser explicado como sendo um problema econômico. $\mathrm{O}$ agricultor assim procederia. uma vez que o preço de exploração do recurso seria superior ao que o mercado poderia pagar por ele; daí a razăo de sua inutilidade, pelo fato de as madeiras para aquelas condições do produtor serem um bem livre, dada a disponibilidade de madeira na área e do seu baixo custo seria pouco estimada. $\left({ }^{6}\right)$ A construção de estradas ou de indústrias madeireiras, tornam a extração эconômica, passando, nesta segunda etapa, a sua exploração.

\section{Final DO PROCESSO DE EXTRATIVISMO}

A fase final do extrativismo pode ser interpretada como sendo o esgotamento de seus recursos naturais ou dada a rigidez da oferta. Para o extrativismo por aniquilamento com o deslocamento da curva de oferta para a esquerda, pela redução dessas fontes de recursos, levando por conseguinte a elevação dos preços a cada nível de equilíbrio (') (Fig. 1C). A longo prazo, por não atender a exigência da demanda, dado o nível de rigidez de preços, a partir do qual não seriam suportados maiores aumentos, tendendo a aumentar o excesso da demanda positiva levando a uma instabilidade warlasiana (Bilas, 1973; Friedman, 1971).

Para o extrativismo de coleta, dado o fato de atingir o ponto em que a oferta passaria a ser inelástica, onde os preços atingiram níveis tão elevados que scriam estimuladas as formas racionais de cultivo ou criação, levando ao sou abandono ou a sua aubatitulọa por outras atividades (Fig. 1c). No extrativismo de coleta, é comum também verificar o aniquilamento em busca de obter maior produtividade imediata, por exemplo, os seringueiros danificarem as árvores com o intuito de obter maior produção, sugerindo uma curva de oferta a curto prazo negativamente inclinada. $\left({ }^{8}\right)$

Para algumas espécies, a exploração extrativa é feita tanto por aniquilamento para uma finalidade e de coleta para outra finalidade. Como exemplo desse caso típico, temos o da palmeira do açaí, na qual são obtidos o palmito por aniquuilamento e o suco pela coleta de seus frutos.

Mesmo para o extrativismo de coleta, não deixam de ser aniquilados, uma vez que estes não fazem parte de uma exploração racional, por depredação, aumento de uma produtividade imediata ou a sua substituição por outras atividades mais competitivas.

\section{CONCLUSÕES GeraIs}

A exploração extrativa não se faz de maneira isolada, mas envolve todo um complexo rural, urbano e industrial, com vinculaçōes no mercado nacional e internacional. Por exemplo, com o crescimento das cidades da Região Norte, aumentando consideravelmente as importações de produtos industrializados do centrö-sul criou-se um fluxo para a maior exploração extrativa de madeira na região.

O processo de extrativismo é iniciado quando esta deixa de ser um bem livre, com o crescimento da demanda. O final do extrativismo, dá-se quando há o esgotamento com o seu aniquilamento ou quando a sua oferta

(6) - A este aspecto deve acrescentar-se a dispersão humana na região, a grande distância aos mercados tornando elevado o custo de transferência e do sistema social no processo extrativo. Quanto à abordagem do problema de mắb-de-obra no processo extrativo uma autorização econômica será divulgada posteriormente.

(7) - Esta pressuposição bascia-se para um determinado espaço geográfico e num horizonte a longo prazo. A curto prazo e com a entrada gradativa de novas áreas extrativas, pode haver o deslocamento da curva da oferta para a direita, levando por conseguinte a uma queda nos preços reais do recurso, tanto para o extrativismo de aniquilamento como de coleta.

(8) - Para o extrativismo, há uma necessidade de desen volver modelos teóricos de oferta levando-se mais em con-

- ta os aspectos dinâmicos acima levantados do que, por exemplo, a simples pressuposição do conceito nerloviano (Nerlove, 1958). 


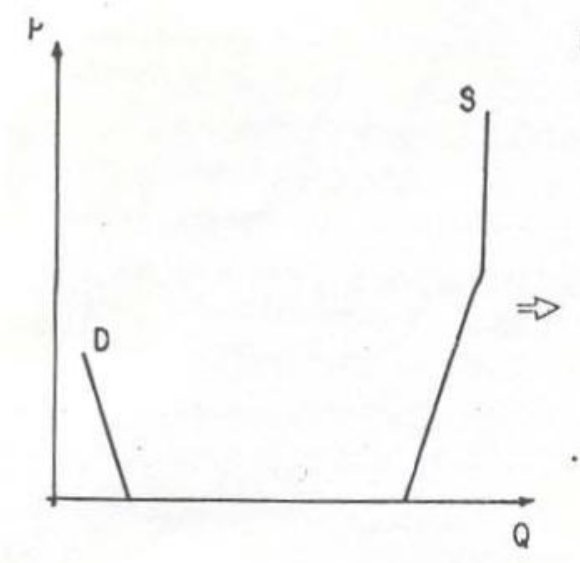

(a)

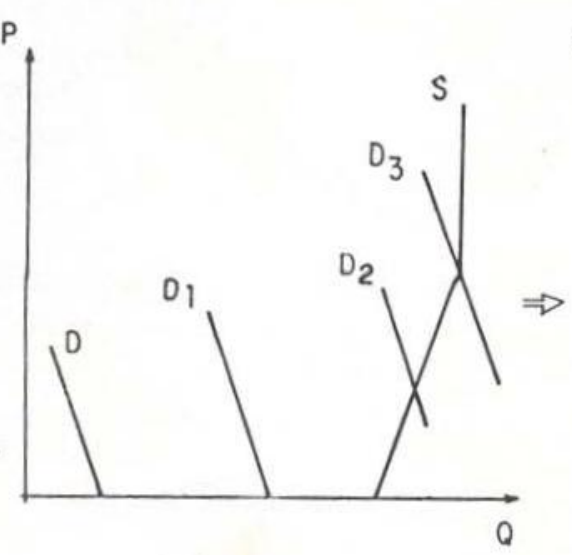

(b)

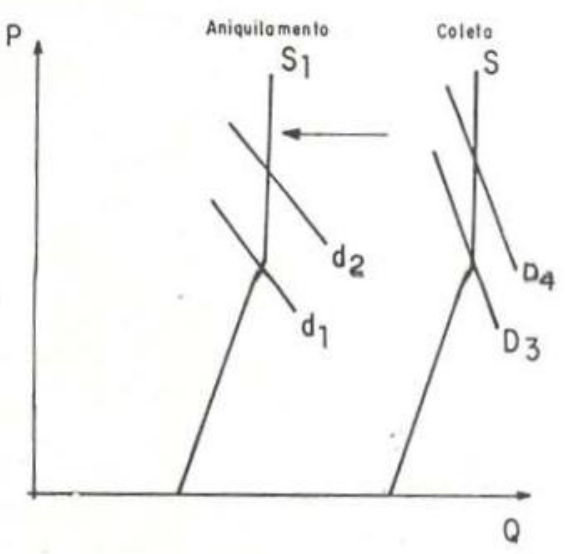

(c)

Fig. 1 - Potencial de recurso extrativo, processo inicial e fase final do extrativismo por aniquilamento e coleta.

se torna inelástica para satisfazer a demanda. Em ambos os casos os niveis de equilíbrio são atingidos com a elevação constante nos preços $\left({ }^{?}\right)$. Nas duas situações, a não existência de produtos substitutos adequados pode levar ao aperfeiçoamento do seu processo de produção, via tecnologia, passando à exploração racional, cuja demanda de tecnologia pode ficar regulada pelo mecanismo de autocontrole e pelo fato de a competição com produtos artificiais, produçăo em bases domésticas serem altamente dispendiosas ou da inviabilidade de sua domesticação. $\left({ }^{10}\right)$

A teoria exposta permite delinear tratamentos distintos para o extrativismo quanto ao sentido de sua preservação. No caso do extrativismo por aniquilamento a limitação da expansão da demanda através do aumento de seu custo de exploração, tais como impostos, taxas, a não execução de obras infraestruturais e outros podem retardá-los ou dificultálas, mas a longo prazo torna-se incvitável a sua exploração. (") Há o perigo de que pelo seu baixo custo, feria pouco estimado. levando à exploração predatória e seletiva; neste caso, o Governo deveria estimular a explora- ção mais racional e possível desse recurso. Paralelamente, o Governo deve procurar estabelecer áreas ou espaços destinados a sua preservação, tais como reservas, parques e fiscalização.

No caso de extrativismo por coleta, a política a ser seguida seria evitar a depredação desses recursos, estabelecendo padrões mais rígidos para a sua manutenção e evitando a sua substituição indiscriminada por outras atividades competitivas.

Comum para anbas as formas de extrativismo, seria uma política visando a desenvolver pesquisa para que a médio e a longo prazo possibilitem a elaboração de tecnologias para desenvolver estas atividades em bases racionais. Nesse elenco, colocam-se também os recursos extrativos potenciais que poderão tornar adequados a sua utilização pela descoberta de alternativas de uso ou que apresentam viabilidade pela domesticação.

Outras medidas são ligadas ao incentivo para o plantio ou criação racional de recursos extrativos que devem ser estimulados não só nas áreas onde são desenvolvidas estas atividades, mas também nas de consumo desses

(9) - Apesar da inexistência de comprovação empírica, é possivel que com a perda do monopólio extrativo com a concorrência de produtos artificiais ou sua exploração em bases racionais o nivel de preços decresça a fim de acompanhar a dos produtos substitutos ou das explorações racionais.

(10) - Este aspecto representa uma crítica ao mecanismo de autocontrole na difusão de técnicas modernas proposta por Paiva (1975).

(11) - É posึsivel que os solos menos férteis e inóspitos para o desenvolvimento da agricultura mantenham a competitividade do extrativismo por mais tempo. 
produtos extrativos. Nesse caso, o reflorestamento constituiria um exemplo típico. Alternativas dirigidas para a área de educação da população no sentido de maior preservação dos recursos naturais, uma política de assistência social dirigida aos extratores e a formulação de padrões mais rígidos para o estabelecimento de outras atividades em substituição às atividades extrativas devem ser estimuladas.

Finalmente, deve ressaltar-so que, no sistema de livre mercado $\left({ }^{12}\right)$, a orientação das atividades no extrativismo pela mão invisível de Adam Smith na ação dos indivíduos em promoverem o interesse público são prejudicadas para atingir o estágio do ótimo de Pareto ( $\mathrm{Bi}$ las, 1973; Henderson \& Quandt, 1976). Quando se busca obter o seu aproveitamento leconômico e o sentido de preservação ecológica, uma vez que os recursos extrativos quando deixam de ser bens livres passam a ser reguladas pelas forças do mercado, porém com a diferença de que apresentam uma oferta rígida, necessitando de um tratamento diferenciado dos recursos não extrativos, pode afirmarse que na região amazônica, a exploração adequada e a preservação repousam também nas mãos de empresários individuais, uma vez que $o$ interesse público se subordinou ao interesse privado.

\section{SUMMARY}

A theoretical model to understand two kinds of exploitation (through gathering and through elimination) is proposed. Specifical treatments for exploration, preservation and conservation are suggested as well as is provided explanation on the dynamic of the exploitation process, from the beginning to the end, and the difficulties envolvad in harmonizing both, free and market goods, aiming the conservation and preservation of natural resources and their economical utilization.

\section{REFERENCIAS BIBLIOGRAFICAS}

BENCHIMOL, Samuel

1966 - Estrutura geo-social e econômica da Amazonla. Manaus, Ed. Governo do Estado to Amazonas, 2v. (Série Euclides da Cunha, 5).

BILAS, Richard A.

1973 - Teoria micro-econômica: uma análise gráfica. Rio de Janeiro, Forense, 404p.

FRIEDMAN, Milton

1971 - Teoria dos preços. Rio de Janeiro, APEC. 320p.

HENDERSON, J.M. \& QUANTD, Richard E.

1976 - Teoria micro-econômica: uma abordagem matemática. Săo Paulo, Pioneira, 417p.

MENDES, Armando Dias

1971 - A Amazônia e o extrativismo. R. econ. BASA, Belém 1 (3): 5-7.

NERLOVE, Marc

1958 - Distributed lags and estimation of long run supply and demand elasticities: theoretical considerations. Journal of Farm Economics, 40 (2): $301-11$.

PAIVA, Ruy Miller

1975 - Modernização e dualismo tecnológico na agriçultura: uma reformulação. Pesq. Plan. Econ., 5 (1): 117-161.

REIS, Arthur Cesar Ferreira

1953 - O seringal e o seringueiro. Rio de Janeiro, Serviço de Informação Agrícola do Ministério da Agricultura, 149p (Documentário da Vida Rural, 5).

RITTER, Wigand

1975 - Natural Resources in Developing Countries. Natural Resources and Development, (1): 44-58.

SHUMPETER, Joseph A.

1961 - Teoria do desenvolvimento econômico. Rio de Janeiro, Fundo de Cultura, 329p.

(Aceito para publicação em 22/06/81)

(12) - Num sistema de livre mercado a busca de lucros shumpeterianos leva a procura de maiores beneficios privados em relação a de maiores benefícios sociais (Shumpeter, 1961).

Uma tentativa... 